\title{
Perfil Proteico y Peptídico de una base Fluida para Bebidas Funcionales obtenida por Fermentación de Lactosuero
}

\author{
Juan P. Conti ${ }^{(1)^{*}}$, María C. Ceriani ${ }^{(2)}$, Marcela A. Juliarena ${ }^{(2)}$ y Eduardo N. Esteban ${ }^{(3)}$ \\ (1) Comisión de Investigaciones Científicas de la Provincia de Buenos Aires (CIC), \\ Calle 526, La Plata, Buenos Aires-Argentina (e-mail: contijp@vet.unicen.edu.ar) \\ (2) Consejo Nacional de Investigaciones Científicas y Técnicas (CONICET), \\ Av. Rivadavia 1917 Buenos Aires-Argentina. \\ (3) Departamento SAMP, Facultad de Ciencias Veterinarias, Universidad Nacional del \\ Centro de la Provincia de Buenos Aires, Pinto 399, Tandil, Buenos Aires-Argentina.
}

${ }^{*}$ Autor a quien debe dirigirse la correspondencia

Recibido May. 18, 2011; Aceptado Jul. 19, 2011; Versión Final recibida Sep. 08, 2011

\section{Resumen}

Se estudiaron proteínas y péptidos presentes en el lactosuero fresco y luego de su procesamiento para transformarlo en una base fluida apta para preparar bebidas funcionales. Con la técnica SDS-PAGE (electroforesis en gel de poliacrilamida con dodecilsulfato sódico) se halló una digestión total de proteínas de alto peso molecular como lactoferrina y seroalbúmina. Las cadenas pesadas de inmunoglobulinas sufrieron una digestión parcial y las cadenas livianas no fueron afectadas. Las proteínas mayoritarias $\beta$-lactoglobulina y $\alpha$-lactoalbúmina tampoco sufrieron modificaciones. El análisis peptídico del lactosuero fresco y la base fluida mostró un profundo cambio del perfil post fermentación, con una distribución de 1.000 a 6.000 Dalton. El rango de péptidos pre-fermentación fue de 1.500 a 18.000 Dalton. El proceso de fermentación provocó un descenso de $\mathrm{pH}$ a 3.5 y aumento la estabilidad térmica de las proteínas. Los resultados permiten concluir que el lactosuero transformado por este método es una base fluida apta para diseñar bebidas funcionales.

\section{Protein and Peptide Profile of a Fluid base for Functional Beverages obtained by Whey Fermentation}

\begin{abstract}
Proteins and peptides present in fresh whey and after fermentation to be transformed in a fluid base appropriate to prepare functional beverages were studied. With the SDS-PAGE technique (sodium dodecyl sulfate polyacrylamide gel electrophoresis) it was observed total digestion of high molecular weight proteins such as lactoferrin and serum albumin. Immunoglobulin heavy chains suffered a partial digestion and the light chains were not affected. The major proteins $\beta$ lactoglobulin and $\alpha$-lactalbumin did not experience any change. The peptide analysis of the cool whey and base fluid showed a profound change in the post-fermentation profile, with a distribution of 1.000 to 6.000 Dalton. The range of pre-fermentation peptides was 1.500 to 18.000 Dalton. The fermentation process caused a decrease in $\mathrm{pH}$ to 3.5 and increased the thermal stability of proteins. The results suggest that whey transformed by this method is a suitable fluid base for designing functional beverages.
\end{abstract}

Keywords: whey, functional drinks, bioactive peptide, lactobacilli, yeast 


\section{INTRODUCCIÓN}

El notable aumento del consumo de bebidas con alto azúcar se asocia al incremento de la grasa corporal, lípidos sanguíneos, secreción de insulina y apetito desmedido. Las consecuencias son enfermedades como la obesidad, diabetes e hipercolesterolemia.

Las dietas ricas en proteínas, especialmente altas en aminoácidos esenciales (EAA), aminoácidos ramificados (BCAA) y en especial Leucina (Leu), se asocian a la pérdida de peso, reducción de grasa corporal, aumento de la síntesis de proteínas musculares, reducción de la secreción de insulina y nivel de triglicéridos plasmáticos (Etzel et al., 2004). Por lo tanto, es posible intervenir para controlar e inclusive prevenir este creciente número de afecciones en nuestra comunidad, mediante la oferta de alimentos funcionales conteniendo proteínas de alto valor biológico. El precio de la leche es menor al de todas estas bebidas e incluso en algunos casos, al del agua embotellada. Las proteínas de la leche contienen más EAA, BCAA y Leu que las proteínas promedio, incluida la proteína de soja. La leche tiene un valor nutricional óptimo; sin embargo, su consumo es menor debido a la mayor penetración en el mercado de las bebidas conteniendo alto azúcar y saborizantes.

La leche es la materia prima con la cual se elabora el queso. La producción de quesos demanda gran cantidad de leche, para obtener un kilogramo de queso se necesitan aproximadamente 10 litros de leche y se generan 9 litros de lactosuero como subproducto. El suero de leche es el residuo líquido que se obtiene mayoritariamente después de la separación de la cuajada en la elaboración de quesos. En términos promedio, contiene más de la mitad de los sólidos presentes en la leche original, incluyendo alrededor del $20 \%$ de las proteínas, la mayor parte de lactosa minerales y vitaminas solubles. De acuerdo a un trabajo de la FAO, el suero, residuo líquido de la fabricación de queso y caseína, es una de las mayores reservas de proteínas alimentarias que quedan todavía fuera de los canales del consumo humano. Resulta paradójico que aún en la actualidad se siga desperdiciando una gran proporción de los litros totales que se generan día a día. Tradicionalmente, se consideraba al suero como un elemento no deseable, de escaso interés y de alto costo de eliminación.

La práctica más común ha sido sencillamente verterlo en los cursos de agua, lo que es muy perjudicial desde el punto de vista ambiental. En efecto, se puede estimar que una fábrica de queso que procesa 280.000 litros de leche cruda por día, por ejemplo, produce alrededor de 250.000 litros de suero líquido y puede contaminar tanta agua como una ciudad de 50.000 habitantes. Una práctica menos perjudicial ha sido y es de uso muy frecuente: el suministro a los terneros o cerdos para complementar su alimentación (Aider et al., 2009).

Al desarrollarse la industria quesera, resultó evidente que estas soluciones tradicionales no eran suficientes para afrontar el problema de la eliminación del suero. Se elaboraron reglamentos anticontaminación que se fueron aplicando progresivamente en los países donde más abundante es la producción de sueros, lo que obligó a los fabricantes de quesos a elaborar el suero o a disponer instalaciones propias de eliminación. La producción de suero en polvo y concentrado de proteínas para consumo animal y humano es la practica más común de los últimos años.

Si bien es cierto que el vertido del suero en los cursos de agua continúa siendo un grave problema ambiental principalmente en los países en desarrollo, esta práctica se ha reducido mucho sobre todo en los países industrializados gracias a la aplicación estricta de medidas contra la polución.

Paralelamente, estas medidas han contribuido también a intensificar la investigación sobre los usos alternativos del suero, constituyendo así un ejemplo del modo en que los incentivos y la reglamentación pueden inducir a que las mismas industrias transformen los residuos contaminantes que generan en productos de alto valor agregado para su propio beneficio (Koutinas et al.,2009). 
Diferentes estudios han demostrado que las proteínas de la leche y el lactosuero tienen en su secuencia codificados péptidos bioactivos, que son inactivos dentro de la secuencia de la proteína intacta y pueden ser liberados por acción de enzimas proteolíticas nativas de la leche, enzimas de bacterias ácido lácticas o durante la digestión gastrointestinal (Korhonen et al., 2003), lo que ha dado lugar a su estudio para introducirlo en la elaboración de alimentos funcionales (Madureira et al., 2007; Pihlanto, 2001).

Los péptidos derivados de las proteínas caseicas y séricas han demostrado poseer varias propiedades bioactivas como: Actividad opioide, antihipertensiva, antimicrobiana, inmunomodulatoria, transporte de minerales y antitrombótica (Rhicha et al., 2007; Fitzgerald et al., 2003).

Los péptidos bioactivos son péptidos que además de aportar su valor nutricional por ser fuente de aminoácidos, son capaces de ejercer efectos biológicos específicos. Muchos de los péptidos bioactivos son muy poderosos, aun en cantidades nutricionalmente insignificantes pueden ejercer efectos fisiológicos. Actualmente en Japón se comercializa, una bebida a base de leche fermentada rica en tripéptidos VPP e IPP, capaces de inhibir la enzima convertidora de angiotensina con el fin de disminuir la presión arterial. (Calpis Co., Ltd., Tokyo, Japón).

El suero de la industria quesera contiene aproximadamente un $0.6 \%$ de proteínas. La $\beta$ lactoglbulina (BLG) es la proteína mayoritaria $53 \%$ y la a-lactoalbúmina (ALA) ocupa el segundo lugar $13 \%$, también tienen en cantidades menores de inmunoglobulinas, lactoferrina, albúmina, proteasa peptona y glicomacropéptido, este ultimo pasa al suero después de la acción de la renina sobre la k-caseína en el proceso de elaboración (Benítez et al., 2008).

La BLG es la proteína más abundante del lactosuero bovino está ausente en la leche humana, es altamente resistente a la digestión gástrica y es la principal causante de la intolerancia oral y alergia a la leche de vaca, especialmente en niños menores de 3 años ( El Zahar et al., 2005; Hoist et al., 1998). La hidrólisis de esta proteína puede potencialmente reducir su alergenicidad y aumentar su digestibilidad por medio de la liberación de aminoácidos y péptidos pequeños que son fácilmente absorbidos en el intestino (Peñas et al., 2006). Las BLG son proteínas muy termolábiles, y por lo tanto inestables a tratamientos térmicos. (Sbodio et al., 2010) Tratamientos industriales como esterilización, calentamiento o presión hidrostática alta mejoran su digestibilidad (Pescumma et al., 2008).

Las bacterias ácido lácticas (BAL) son ampliamente utilizadas en la industria alimentaria como cultivos iniciadores y/o adjuntos en la elaboración de diversos productos fermentados (LeRoy et al., 2004). Recientemente, se ha demostrado que algunas BAL son capaces de degradar las proteínas del lactosuero y de hidrolizar la porción alérgica de la BLG (Priult et al., 2005; Bertand et al., 2003; El Zahar et al., 2003). Todas estas propiedades convierten a las BAL en una alternativa interesante para ser utilizadas en la elaboración de bebidas fermentadas de lactosuero. Estas tendrán menor contenido de lactosa, mayor concentración de aminoácidos libres, mejor digestibilidad de sus proteínas y/o reducido contenido alergénico (Guanhao et al., 2010).

El objetivo de este trabajo es el análisis proteico y peptídico de esta base fluida obtenida luego de la fermentación del lactosuero con una comunidad microbiana recientemente descripta.

\section{MATERIALES Y MÉTODOS}

\section{Fermentación del lactosuero fresco y obtención de la base fluida:}

El lactosuero fresco proveniente de una planta quesera con $\mathrm{pH} 6 \pm 0.4$, se desgrasó por centrifugación a $7.000 \mathrm{rpm}$ con un flujo continuo de $4.167 \mathrm{~mL} /$ minuto y a una temperatura de $10^{\circ}$ C. Luego de la centrifugación fue microfiltrado sucesivamente a través de membranas de 5.1 y $0.5 \mu \mathrm{m}$ de poro y finalmente a través de una membrana esterilizante con tamaño de poro de 0.1 $\mu \mathrm{m}$. El lactosuero estéril se envió al reactor donde se fermentó durante 24 a 48 horas a una temperatura de $37^{\circ} \mathrm{C}$ en anaerobiosis. Transcurrido ese tiempo, el pH del medio descendió a 3.5 
y la presión interna del reactor se elevó a $0.7 \pm 0.2 \mathrm{Kg} / \mathrm{cm}^{2}$. Para obtener la base fluida el lactosuero fermentado se centrifugó a $7.000 \mathrm{rpm}$ para sedimentar la biomasa, y el sobrenadante se ultrafiltró utilizando una membrana con tamaño de poro de 500.000 Dalton.

Fermento utilizado:

Está constituido por una comunidad microbiana (CM) integrada por lactobacterias y levaduras. La caracterización bioquímica y molecular ha permitido la identificación de diversas especies de lactobacterias y dentro de ellas, diversas cepas: Lactobacillus helveticus (4 cepas), Lactobacillus paracasei (2 cepas), Lactobacillus fermentum (3 cepas), Lactobacillus gasseri, Lactobacillus parabuchneri, Lactobacillus casei y Lactobacillus panis.

Los agentes de Eukaria son levaduras de las cuales se han identificado distintos géneros y especies: Pichia kudriavzevii (Issatchenkia orientalis) y Saccharomyces cerevisiae.

\section{Determinación de proteínas totales:}

Se llevo a cabo utilizando el reactivo de ensayo de proteínas BioRad (Cátalogo 500-0006, Richmond CA, USA). Se utilizaron estándares de albúmina bovina (BSA, Sigma) en el rango de $75 \mu \mathrm{g} / \mathrm{mL}$ a $10 \mu \mathrm{g} / \mathrm{mL}$. Las muestras a analizar se procesaron por duplicado, en diluciones sucesivas de 1:100 a 1:200. Las reacciones se llevaron a cabo en placas de 96 pocillos, colocando $100 \mu \mathrm{l}$ de muestra y $25 \mu \mathrm{l}$ de reactivo en cada pocillo. Luego de agitar suavemente, durante 10 minutos, se cuantificó la absorbancia a $595 \mathrm{~nm}$ en un lector automático de microplacas. Con los datos obtenidos, se trazó una curva de calibración y se estimó la concentración de proteínas total en $\mathrm{mg} / \mathrm{mL}$.

\section{Determinación del poder emulsionante de la base fluida sobre proteínas:}

Para determinar el poder emulsionante de la base fluida se utilizó como fuente proteica Lacprodan 80 (Arlafood de Argentina). Lacprodan 80 es proteína de lactosuero concentrada por ultrafiltración hasta el $80 \%$ y deshidratada. Además de la base fluida obtenida como ya se ha explicado, $\mathrm{pH}$ 3.5, se utilizó lactosuero sin fermentar, $\mathrm{pH}$ 6. Se prepararon suspensiones en la base fluida y en lactosuero sin fermentar con 45, 20 y $10 \mathrm{gr} / \mathrm{L}$ de proteína. Adicionalmente, se incorporaron otros recipientes conteniendo solamente la base fluida o el lactosuero sin fermentar. Estos últimos contenían la concentración original de proteínas del lactosuero (6 gr/L). Las suspensiones se distribuyeron en botellas de vidrio transparente termoresistente de $250 \mathrm{ml}$ con tapa a rosca y sello. A fin de esterilizar el producto, las 8 botellas se sumergieron en agua hirviente durante 5 minutos y luego de haber retornado a temperatura ambiente se refrigeraron a $6^{\circ} \mathrm{C}$ durante la experiencia.

Identificación del perfil proteico del lactosuero fresco y base fluida mediante electroforesis en gel de poliacrilamida:

La SDS-PAGE se llevó a cabo según el método de Laemmli 1970). Se preparó un gel al 15\% de acrilamida: bis. Se sembraron $6 \mu \mathrm{g}$ de cada muestra, y un marcador de peso molecular comercial apropiado (Sigma-Aldrich, St. Louis, MO, USA).

Se incorporó en el examen una muestra de leche descremada en polvo y una de lactosuero comercial 35\% (Ilolay, Argentina). Todas las muestras fueron pretratadas con buffer de siembra 2x (0.125 M Tris-HCL, 4\% SDS, 20\% v/v glicerol, 10\% ß-mercapto, 0.02\% de azul de bromofenol, $\mathrm{pH} 6,8)$ y hervidas durante 5 minutos. Se sembraron y se corrieron a $20 \mathrm{~mA}$ hasta que atravesaron el gel concentrador, y luego a 60mA hasta el final de la corrida, en una minicuba para geles verticales (BioRad, Ca. USA). Se utilizó una fuente eléctrica POWER PAC HC (Bio Rad, Ca. USA).

Una vez finalizada la corrida, el gel se sumergió en solución de coloración $(0.1 \%$ Coomasie Blue en $25 \%$ de metanol y $10 \%$ de ácido acético) durante 30 minutos con agitación suave. El gel se decoloró con una solución de $25 \%$ metanol, $10 \%$ acido acético. 
Identificación del perfil peptídico del lactosuero fresco y base fluida mediante espectrometría MALDI-TOF:

Preparación de las muestras: Luego de ajustar el $\mathrm{pH}$ de la base fluida a $\mathrm{pH}$ equivalente al del lactosuero fresco, se ultrafiltraron ambas muestras a través de una membrana de 500.000 Dalton. Se colectaron los filtrados y se autoclavaron a $121^{\circ} \mathrm{C}$ a una atmosfera de presión durante 15 minutos. Se descartaron los precipitados conteniendo proteínas desnaturalizadas, y los sobrenadantes se centrifugaron a $14.000 \mathrm{rpm}$ durante 15 minutos, volviendo a tomar el sobrenadante para ser analizado por espectrometría MALDI-TOF (Coligan et al, 1995). Éste procedimiento se realizo para eliminar la mayor cantidad de proteína y analizar los péptidos.

Se fragmentaron e hicieron MS/MS de tres picos de buena intensidad de la M1 (lactosuero) y uno de la M2 (lactosuero fermentado).

\section{RESULTADOS}

El permeado obtenido por ultrafiltración del lactosuero fermentado luego de ser centrifugado, es la base fluida. Ésta presenta un color amarillento suave, de gran transparencia y sin precipitaciones al ser sometida a tratamientos térmicos extremos $\left(120^{\circ} \mathrm{C}\right.$ durante 20 minutos).

Determinación de proteínas totales:

Lactosuero fresco: $3 \pm 0.6 \mathrm{mg} / \mathrm{mL}$

Base fluida: $2.5 \pm 0.3 \mathrm{mg} / \mathrm{mL}$

Determinación del poder emulsionante de la base fluida sobre proteínas:

Luego de la esterilización, las 4 botellas con la suspensión proteica en lactosuero sin fermentar presentaron un intenso precipitado, proporcional a la concentración de proteínas que contenían. Estas 4 botellas fueron descartadas. En tanto, las 4 botellas con la suspensión proteica en la base fluida no presentaban ningún precipitado. Luego de conservadas a $6^{\circ} \mathrm{C}$ en posición vertical estática, la aparición de vestigios de precipitados se observó en los siguientes tiempos: $45 \mathrm{gr} / \mathrm{L}$ a los 7 días, $20 \mathrm{gr} / \mathrm{L}$ a los 30 días, $10 \mathrm{gr} / \mathrm{L}$ a los 70 días y la botella conteniendo sólo la base fluida a los 120 días.

Identificación del perfil proteico del lactosuero fresco y base fluida mediante electroforesis en gel de poliacrilamida:

En la figura 1 se observa que el perfil electroforético del lactosuero fresco, ubicado en la segunda calle (B) coincide con el perfil electroforético del lactosuero comercial ubicado en la primera calle (A). Las tres bandas de mayor peso molecular corresponden a: lactoferrina (LF), seroalbúmina (SA) y cadenas pesadas de inmunogammaglobulinas (IgGP), seguida de una banda de 25.000 Dalton perteneciente a las cadenas ligeras de $\lg$ (igGL), y dos bandas de bajo peso: $\beta$ lactoglobulina (BLG) y a-lactoalbúmina (ALA). Las muestras de la base fluida (calles $C$ y $D$ ) presentan una total digestión de las primeras dos bandas de alto peso (lactoferrina y seroalbúmina), y la concentración de las cadenas pesadas de (IgG) se ve reducida, lo que indicaría que también hay digestión enzimática para estas cadenas de proteínas. Las cadenas ligeras de IgG no se ven afectadas y las proteínas de bajo peso $\beta$-lactoblobulina y $\alpha$ lactoalbúmina no sufren modificaciones perceptibles por el procedimiento aplicado.

La calle E muestra el patrón electroforético de la leche en polvo descremada, donde se observa claramente la banda perteneciente a las caseínas. Las proteínas séricas no se visualizan probablemente debido a que están en menor proporción. La calle $\mathrm{F}$ es un marcador de peso molecular. 


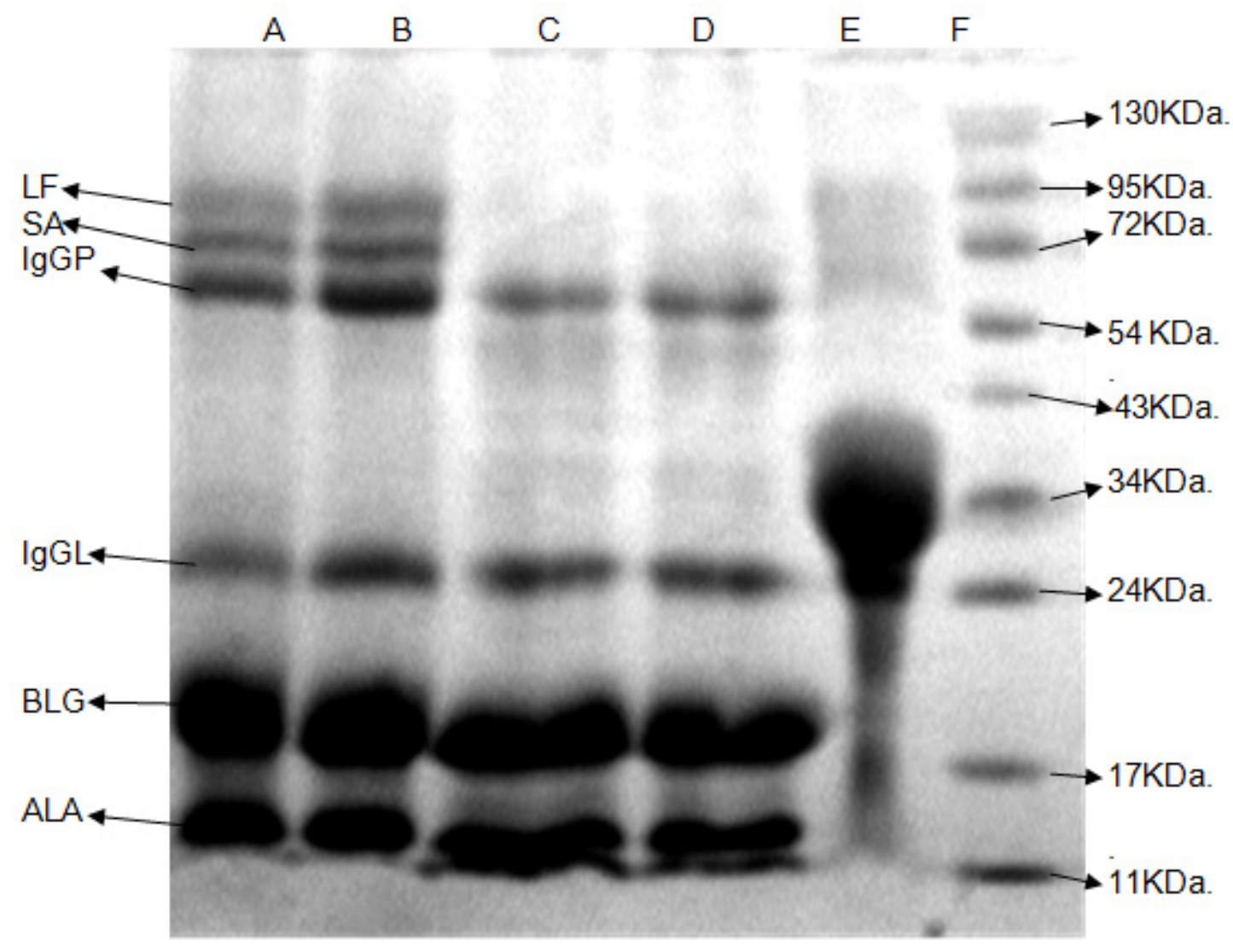

Fig. 1: Gel de poliacrilamida desnaturalizante 15\%. Observación de las bandas proteicas por tinción con Coomasie blue. Calle A: $6 \mu \mathrm{g}$ de lactosuero comercial, Calle B: $6 \mu \mathrm{g}$ de lactosuero fresco, Calle C: $6 \mu \mathrm{g}$ de lactosuero fermentado, Calle D: $6 \mu \mathrm{g}$ de lactosuero fermentado, Calle E: $6 \mu \mathrm{g}$ de leche en polvo descremada, Calle F: $3 \mu \mathrm{g}$ de Marcador comercial.

Identificación del perfil peptídico del lactosuero y base fluida mediante espectrometría MALDITOF:

La figura 2 es una comparación del perfil peptídico realizado en una matriz para péptidos de bajo peso molecular, hasta 2.700 Dalton (ácido hidroxicinámico) en modo reflectrón del equipo del lactosuero fresco (M1) (parte superior de la figura) y la base fluida (M2) (parte inferior de la figura). El lactosuero fresco (M1) contiene péptidos que cubren el rango de 1.500 Dalton a 2.450 Dalton. La base fluida (M2) presentó un notable aumento en la diversidad de péptidos. Estos se distribuyeron en el rango de 1.000 Dalton a 2.500 Dalton. La Fig. 3 compara el perfil peptídico realizado en una matriz para péptidos grandes de hasta 18.000 Dalton (ácido sinapinico) en modo lineal del equipo del lactosuero fresco (M1), (parte superior de la figura) y la base fluida (M2) (parte inferior de la figura). Los resultados muestran que el lactosuero fresco (M1) contiene péptidos en el rango de 4.000 a 18.000 Dalton. La base fluida (M2) presentó péptidos que se distribuyeron en el rango de 3.500 Dalton a 6.000 Dalton. Se observa que los péptidos mayores a 6.000 Dalton que se encontraban en el lactosuero fresco, desaparecen luego de su fermentación y aparecen nuevos péptidos de menor peso molecular. No se visualizaron picos correspondientes a las proteínas mayoritarias del lactosuero (BLG y ALA), debido a que fueron precipitadas y separadas en el proceso de preparación de las muestras. 


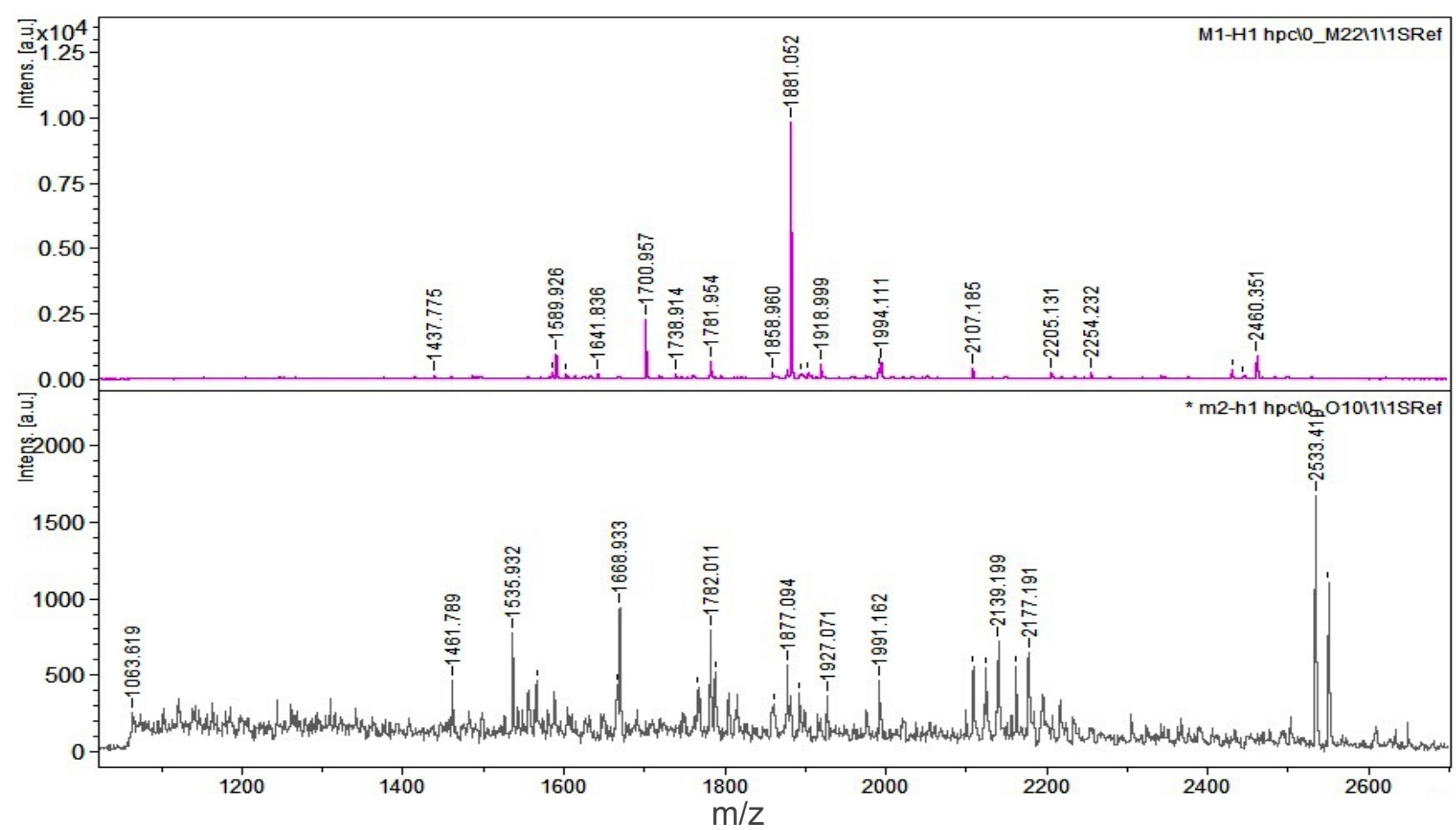

Fig. 2: Comparación del perfil peptídico realizado en una matriz para péptidos chicos hasta 2.700 Dalton (ácido hidroxicinámico) en modo reflectrón del equipo. M2: Se observa la gran diversidad de péptidos producidos por la fermentación. Los picos más sobresalientes no se corresponden con los picos de la muestra no fermentada.

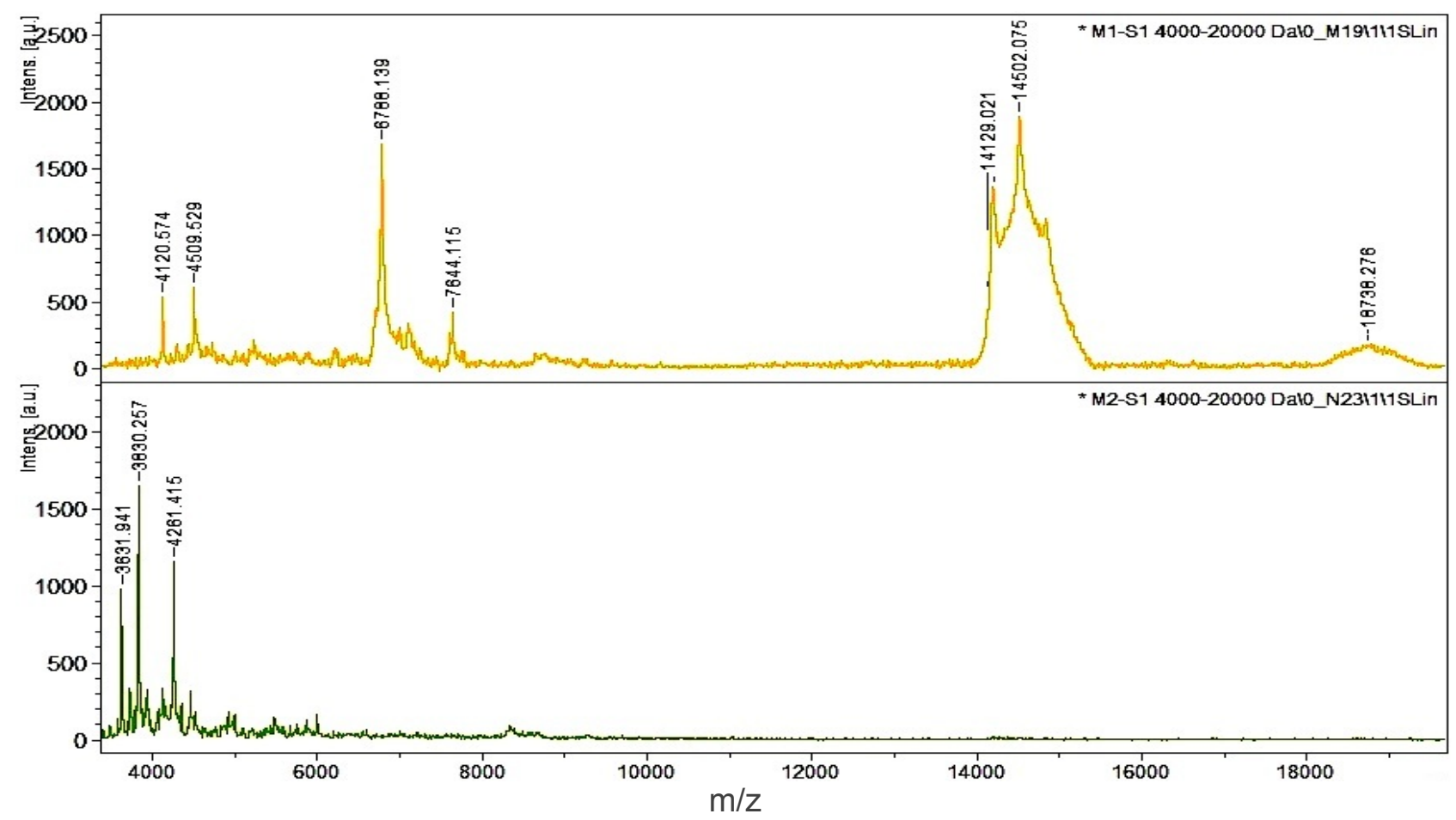

Fig. 3: Comparación del perfil peptídico realizado en una matriz para péptidos grande hasta 18.000 Dalton (ácido sinapinico) en modo lineal del equipo. M2: Se observa que la mayor concentración de péptidos se encuentra entre 4.000 y 6.000 Dalton. 
Identificación de péptidos:

Se fragmentaron e hicieron MS/MS de tres picos de buena intensidad de la M1 y uno de la M2, pudiéndose identificar los tres primeros y no los de $M 2$, debido a la baja intensidad del espectro. Los péptidos resultantes fueron producto de la $\beta$-caseina (YQEPVLGPVRGPFPIIV, QEPVLGPVRGPFPIIV), y a-caseina (RPKHPIKHQGLPQEVLNENLL) respectivamente. Los péptidos derivados de la $\beta$-caseina solamente difieren en un aminoácido en el extremo amino terminal.

\section{DISCUSIÓN}

El análisis electroforético mostró que el perfil proteico de la base fluida coincide con el perfil típico del lactosuero de la industria quesera. Se observa que la comunidad microbiana utilizada no degrada significativamente las proteínas mayoritarias del lactosuero (BLG y ALA). Si bien la BLG puede causar intolerancia gástrica, la estabilidad térmica lograda permite realizar un proceso térmico en el cual la digestibilidad se aumentaría y se reducirían los riesgos de intolerancia oral (Pescumma et al., 2008).

Si bien los procedimientos de electroforesis en gel de poliacrilamida (PAGE) nos permitieron la identificación de las proteínas del lactosuero antes y después de su fermentación, como así también el efecto proteolítico de la comunidad mirobiana, la técnica de PAGE carece de definición para el análisis de los péptidos. La metodología MALDI-TOF (Coligan et al., 1995) resultó el procedimiento de elección para este fin. El proceso de fermentación introduce una modificación sustancial al perfil de péptidos, incrementando en forma notable su variabilidad (Figuras 2 y 3 ). El peso molecular de los mismos es menor a 6.000 Dalton y esto asegura su rápida asimilación por el organismo, aportando energía rápidamente. La base contiene los minerales balanceados y el agua de la leche natural.

El poder emulsionante de la base fluida permite la adición de altas concentraciones de proteínas sin precipitaciones, aún luego del proceso de esterilización y estacionamiento por varios días. Esto hace que su aspecto sea agradable al presentarse en envases transparentes. Es de remarcar que el poder emulsionante de la base fluida es natural y no se requiere el agregado de emulsionantes artificiales como el lauril sulfato de sodio.

La acidez y estabilidad térmica naturales logradas permiten una profunda esterilización sin que se observara la proliferación de levaduras o bacterias durante el período del experimento. Por lo tanto, tampoco es requerido el agregado de conservantes artificiales. La concentración de lactosa en el lactosuero se reduce al ser transformada en ácido láctico durante la fermentación. Este fenómeno reduce los riesgos de intolerancia y adicionalmente, el efecto acidificante del ácido láctico evita el uso de acidulantes artificiales.

La estabilidad térmica, poder emulsionante, acidificación e inhibición de proliferación microbiana lograda con el proceso de fermentación y esterilizado, crea la oportunidad de incrementar la concentración de proteínas y péptidos en la base fluida sin precipitados, cambios sensoriales o alteraciones de las características originales de proteínas y péptidos. Una bebida de estas características, que además no necesita de emulsionantes ni conservantes artificiales, sería considerada de alta proteína y, si sólo se agrega azúcar hasta $60 \mathrm{gr} / /$ también se consideraría de bajo azúcar según los criterios del FDA (Food and Drug Administration). Por lo tanto, podría generarse sobre la base de la tecnología descripta en este trabajo, una familia de bebidas funcionales específicamente diseñadas, conteniendo los niveles y calidad de proteínas que sean requeridos.

\section{CONCLUSIÓNES}

La CM modifica el perfil peptídico hallado en el lactosuero fresco de la industria quesera y sólo parcialmente el perfil proteico, la gran diversidad de péptidos de bajo peso molecular, la reducción significativa del el $\mathrm{pH}$, la estabilidad térmica y poder emulsionante logrados, hacen de la base fluida un recurso natural apto para el desarrollo de bebidas funcionales. 


\section{REFERENCIAS}

Aider, M., D. Halleux y I. Melnikova. Skim acidic milk whey cryoconcentration and assessment of its functional properties: Impact of processing conditions. Innovative Food Science and Emerging Technologies: 10(3), 334-341 (2009).

Benítez, R., A., Ibarz, y J., Pagan. Hidrolizados de proteína: procesos y aplicaciones. Acta Bioquímica Clínica Latinoamericana: 42(2), 227-36 (2208).

Bu G., Y. Luo, Y., Zhang y F., Chen. Effects of fermentation by lactic acid bacteria on the antigenicity of bovine whey proteins. Journal of the Science of food and Agriculture: 90(12), 20152020 (2010).

Coligan, J. E., B. M. Dunn y H.L. Ploegh, Matrix-assisted laser desorption/ionization time-of-flight mass analysis of peptides. In Current Protocols in Protein Science by Speicher, D. W. and P. T. Wingfield (Eds), John Wiley \& Sons, vol 1 (16.2), New York , U.S.A., 1995.

El Zaher, K., J.M. Chobert, M. Dalgarrondo y T. Heartlè.Proteolytic degradation of ewe milk proteins during fermentation of yoghurts and storage. Nahrung/Food: 47,199-206 (2003).

El Zahar, K., M. Sitony, Choiset y F. Metro, Peptic hidrolysis of ovine-lactoglobulin. Exceptional susceptibility of native ovine - lactoglobulin to pepsinilysis. Int. Cairy J: 15, 17-27 (2005).

Etzel M.R., Manufacture and use of dairy protein fractions. J Nutr. Apr:134(4):996S-1002S. Review (2004).

FitzGerald, R.J. y H. Meisel, Milk protein hydrolysates and bioactive peptides.In: Advanced dairy chemistry: Proteins. Fox PH, McSweeney PLH, ed. Academic/Plenum Publishers. pp 675-698, Cambridge, UK (2003).

Harb B., C., I.V. Ivanova, M., Dalgalarrondo y T. Haertlé., Evolution of -lactoglobulin and lactalbumin content during yoghurt fermentation. Int Dairy J: 13, 39-45 (2003).

Hoist, A y S. Haiken, Epidemiology and prevention of cow's milk allergy. Allergy 53 (46), 111-113 (1998).

Korhonen, $\mathrm{H}$ y A. Pihlanto Leppâlâ., Bioactive peptides: new challenges and opportunities for the dairy industry. Aust J Dairy Technol: 5, 129-134 (2003).

Koutinas, A., H. Papapostolou, D. Dimitrellou, N. Kopsahelis, E. Katechaki, A. Bekatorou y L. Bosnea. Whey valorisation: A complete and novel technology development for dairy industry starter culture production. Bioresource Technology: 100(15), 3734-3739 (2009).

Madureira, A., C. Pereira, A., Gómes, M., Pintado y F., Malcata. Bovine whey proteins - overview on their main biological properties. Food Res Int: 40, 1197-211 (2007).

Laemmli, U.K., Cleave of structural proteins during the assembly of the head of bacteria pHage T4. Nature: 227, 680-685 (1970).

Leroy F., De Vuyst L., Lactic acid bacteria as fuctional starter cultures for the food fermentation industry. Trends Food Sci. Technol: 15, 67-78 (2004).

Peñas, E., G. Prestarno, M. Baeza, M. Martinez y R. Gomez, Effect of combined high pressure and enzimatic treatments on the hidrolysis and inmunoreactivity of dairy whey prot. Int Dairy J: 16, 831839 (2006). 
Pescumma, M., E.F. Hérbet, F. Mozzi y G. Font de Valdes, Whey fermentation by thermophilic lactic acid bacteria: Evolution of carbohydrates and protein content. Food Microbiol 25(3), 442-451 (2008).

Pihianto, A., Bioactive peptides derived from bovine whey proteins: opioid and ACE-inhibitory peptides. Trends Food Scl Technol: 11, 347-536 (2001).

Prioult, G., S. Pecquet, y I. Fliss, Allergenicity of acid peptides from bovine lactoglobulin is reduced by hydrolysis with bifidobacterium lactis NCC362 enzymes. Int. Dairy J: 15, 439-448 (2005).

Rhicha S., C., Radha, P., Jamuna y K., Purnima. Whey protein hydrolysate: functional properties, nutritional quality and utilization in beverage formulation. Food Chemistry: 101(4), 1484-1491 (2007).

Sbodio, O.A., E.J., Tercero, M.S., Zannier y G.R., Rivelli. Tratamiento Térmico de leche: Influencia del $\mathrm{pH}$ y $\mathrm{CaCl}_{2}$ en la Elaboración de Queso Cuartirolo. Información Tecnológica: 21(5), 107116(2010). 